\title{
PEMBUATAN MEDIA TANAM BERBAHAN KAIN BEKAS
}

\section{MAKING PLANTING MEDIUM BY USING FABRICS WASTE}

\author{
Shalehoddin ${ }^{1}$, Erwin Ashari ${ }^{2}$, \\ 1,2 Prodi Pendidikan Bahasaa Inggris, FKIP, Universitas Riau Kepulauan, Batam, Indonesia \\ 그ibond501@gmail.com, ${ }^{2}$ erwinasahariharianja83@gmail.com
}

\begin{abstract}
Abstrak
Penanganan permasalahan sampah bukan hanya tanggungjawab pemerintah saja, tetapi merupakan tanggung jawab setip orang. Sampah rumah tangga bisa diminamilisir dengan menggunakan $3 R$ (Reuse, Recyle, Reduce). Salah satu sampah rumah tanga adalah pakaian dan kain bekas yang tidak layak pakai. Dengan menggunakan metode recycle, kain bekas dan pakaian yang tidak layak pakai tersebut bisa dijadikan menjadi barang yang bisa dimanfaatkan seperti media tanam. Hal tersebut telah dilakukan dilaksanakan Perumahan Sawang Permai RW XI, Kelurahan Buliang, Kecamatan Batu Aji, Kota Batam. Melalui pelatihan yang dilaksanakan pada tangal 26 sampaidengan 27 agustus 2017, maka sampah masyrakat telah bisa didaur ulang menjadi barang yakni media tanam untuk tanaman hias maupun sayur mayur yang sangat cocok untuk daerah yang padat penduduk. Dari hasil pelatihan dapat terihat bahwa ada perubahan yang signifikan di lingkungan masyarakat tentang kesadaran dalam bercocok tanam dengan mengunakan media tanam pot, hal tersebut terlihat dari banyaknya jumlah media tanam berbahan kain bekas dan kain bekas yang tidak layak pakai baik dipekarangan rumah warga maupun di tempat yang strategis di dalam perumahan tersebut.
\end{abstract}

Kata Kunci ; Sampah Rumah Tangga, 3r (Reuse, Rcycle, Reduce), Kain Bekas, Media Tanam.

\section{Abstract}

Handling waste issue is not only the government's responsibility, but it is also community's. Community waste can be minimized using $3 R$ (Reuse, Recycle, Reduce). One of the house waste is unusable wearing fabrics waste. By using the Recycle Method, unusable wearing fabrics waste can be used as goods that can be utilized as a planting medium. This has been done implemented at Perumahan Sawang Permai RW XI, Buliang, Batu Aji District, Batam. Through the training which held on 26th day on 27 August 2017,comunity's unusable wearing fabrics waste can be recycled into goods as planting media for ornamental plants and vegetables that are suitable for large populated areas. From the training results can be seen that there was a significant change in the community's awareness in cultivation by using planting medium, it was seen from the number of growing planting media by using unusable wearing fabrics waste either at house's environtment and strategical places around housing estate. 
Minda Baharu, Volume 2, No 1 Juli 2018

Keywords; Community Waste, 3R (Reuse, Rcycle, Reduce), Fabrics Waste, Planting Medium.

\section{PENDAHULUAN}

Masalah sampah merupakan masalah yang selalu sorotan di daerah perkotaan. Menurut Yuwono (2010), sampah merupakan sisa hasil dari suatu usaha atau kegiatan yang berwujud padat, wujudnya bisa berupa zat organik maupun anorganik yang bersifat dapat terurai maupun tidak terurai dan dianggap sudah tidak berguna lagi sehingga layak untk dibuang. Jadi bisa dikategorikan bahwa memang sampah tidak bisa lepas dari kehidupan manusia, sebab sampah merupakan hasil dari kegiatan manusia. Yang amenjadi persoalan adalah bagaimana mengatasi dan mengelola sampah tersebut agar tidak menimbulkan atau mengundang penyakit kepada manusia. Adapun yang bisa dilakukan adalah dengan melakukan 3R (Reuse, Recycle, dan Reduce). Ketiga metode ini bisa meminimalisir penumpukan sampah pada masyrakat.

Pemerintah sudah melakukan beberapa langkah dalam mengatasi masalah tersebut sebagaimana yang tertuang dalam Undang - undang no. 18 tahun 2008 tentang Pengelolaan Sampah dan Peraturan Pemerintah no. 81 tahun 2012 tentang Pengelolaan Sampah Rumah tangga dan Sampah sejenis Sampah Rumah Tangga yang memaparkan tentang permasalahan sampah dan cara mengatasinya. Sampah Sampah limbah rumah tangga kebanyakan berakhir di TPA (Tempat Pembuangan Akhir). Sampah sebenarnya bukanlah sepenuhnya tanggung jawab dinas kebersihan pemerintahan setempat, akan tetapi merupakan taggung jawab bersama, pemerintah daerah dan masyrakat tersebut, seperti yang disampaikan oleh Yarianto (2005) dalam Yuni Puspitawati dan Mardwi Rahdriawan (2012) bahwa Keterlibatan masyarakat dalam pengelolaan sampah adalah salah satu faktor kunci untuk menanggulangi persoalan sampah perkotaan.

Kalau ditelisik lebih cermat, salah satu sampah yang dihasilkan masyrakat adalah pakaian dan kain bekas yang sudah tidak layak pakai. Biasanya sampah tersebut berakhir di TPA (Tempat pembuangan Akhir, dan hanya sebagian kecil yang menggunakan tersebut sebagai alas kaki dan kain lap. Sengkan sampah tersebut bisa didaur ulang menjadi barang yang bisa digunakan seperti menjadikannya sebagai media tanam. 
Kota Batam merupakan salah satu kota industri dan padat penduduk. Kepadatan penduduk di perumahan perumahan menghasilkan berton-ton sampah setiap harinya. Seperti yang dikabarkan oleh Batam Today.com, yang dilansir pada tanggal 22 November 2016, menurut Kepala Bidang Kebersihan DKP Batam, Fairis Batubara, beliau menyampaikan bahwa produksi sampah yang paling banyak yakni di wilayah yang padat penduduknya Kecamatan Sagulung dan sekitar Batuaji. Dari stastistik jumlah produksi sampah di wilayah Sagulung per-hari mencapai 181 ton baik dari sampah rumah tangga maupun di pertokoan . Seperti perumahan lain yang ada di Kota Batam, Perumahan Sawang Permai RW XI, Kelurahan Buliang, Kecamatan Batu Aji, Kota Batam adalah perumahan penyumbah sampah di daerah Batu Aji, Batam dan perumahan ini juga termasuk perumahan yang dihuni oleh para pekerja di perusahaan yang tersebar di Kota Batam. Umumnya para pekerja didominasi oleh para kepala keluarga, sedangkan ibu rumah tangga lebih condong ke wiraswasta dan sebagian besar hanya berprofesi sebagai ibu ramah tangga saja. Keadan di perumahan tersebut juga dikategorikan sebagai pemukiman yang padat penduduk, sedangkan penduduknya berasal dari berbagai suku, ras dan agama. Dengan keadaan seperti itu, maka perumahan tersebut adalah perumahan yang dihuni oleh masyarakat urban.

Sebagai masyarakat urban atau masyrakat perkotaan, sudah menjadi suatu kebiasaan bagi mereka untuk memperindah pekarangan mereka dengan tanaman bunga maupun apotek hidup. Tapi keinginan tersebut terhalangi oleh pemukiman yang padat sekali, sehingga para penduduk memilih alternatif yaitu dengan menggunakan pot bunga sebagai media tanam. Alternatif yang mereka pilih kebanyakan dari dari ember bekas yang tidak bisa dipakai lagi, dan jumlahnya pun sangat sedikit. senhingga media tanam bergantung pada rusak tidaknya ember warga yang rusak.

Pertama kali memasuki pemukiman tersebut, sudah ada beberapa pot bunga di depan rumah warga perumahan, tetapi jumlahnya sangat sedikit. setelah melakukan dialog dengan warga yang dipandu dengan Ketua RT dan RW maka diperoleh informasi bahwa sebenarnya mereka memiliki keinginan yang kuat untuk memperindah perumahn tersebut dengan memanam berbagai jenis bunga baik di depan rumah maupun ditempat strategis di pingir jalan, sehingga akan membuat perumahan tersebut lebih asri dan indah. Akan tetapi 
dikarenakan kebutuhan hidup dan biaya anak sekolah, maka budget untuk membeli pot dikurangi, artinya hanya akan dibeli jikalau semua kebutuhan pokok dan keperluan sekolah anak sudah terpenuhi. Menurut cerita mereka hal tersebut tidak bisa dilakukan setiap hari karena gejolak ekonomi yang tak menentu dan kebutuhan anak sekolah pun semakin hari semakin meningkat. Berdasarkan hal tersebutlah maka muncul dibenak tim untuk mencarika solusi terhadap masalah tersebut.

Setelah melakukan diskusi yang panjang dengan tim maka muncullah ide kreatif dalam tim untuk melakukan pelatihan mengatasi persoalan tersebut dengan cara memberikan ilmu untuk memanfaatkan pakaian atau kain bekas yang sudah tak layak pakai untuk dijadikan pot bunga atau media tanam lainnya. Dengan begitu warga perumahan bisa memanfaatkan pakaian atau kain bekas tak layak pakai menjadi sesuatu hal yang berguna.

\section{METODOLOGI}

\section{Bentuk Kegiatan}

Berdasarkan persoalan diatas, maka tim mengadakan kegiatan pelatihan pelatihan pembuatan media tanam berbahan kain bekas. Pelatihan tersebut dilakukan dengan melakukan demonstrasi langsung di depan ibu-ibu PKK sehingga ibu-ibu PKK dapat melihat secara langsung dan ikut berpartisipasi di dalamnya sehingga lebih mudah dipahami oleh ibuibu PKK dan setiap kendala yang dihadapi bisa langsung diatasi dengan baik. Pelaksanaan kegiatan terdiri atas tiga langkah utama, yaitu : perencanaan, tindakan dan evaluasi.

\section{a. Perencanaan}

Pada kegiatan perencanaan tim pelaksana mengundang ibu-ibu PKK untuk dijelaskan maksud, tujuan dan teknis pelaksanaan kegiatan sosialisasi, hal ini dilakukan setelah tim sudah melakukan diskusi interen dan diskusi dengan Bapak RT dan Bapak RW setempat sehingga kegiatan tersebut menjadi terprogram dengan baik.

b. Tindakan

Tindakan yang dilakukan adalah dengan mendemonstrasikan langsung di depan ibu-ibu-ibu PKK cara pengolahan dan cara pembuata media tanam dengan berbahan pakaian atau kain bekas yang sudah tidak layak pakai dengan campuran semen yang 
sudah di campur air. Sewaktu melakukan demonstrasi, tim juga menjelaskan ukuran, takaran bahan dan media lain yang diperlukan seperti ember yang digunakan sebagai media cetak. Setiap ibu-ibu PKK mengalami kendala maka tim dengan sigap membantu.

c. Evaluasi

Evaluasi bertujuan untuk melihat hasil dari pelatihan tersebut. Hasil yang dimaksud adalah produk yang dihasilkan oleh ibu-ibu PKK setelah ikut melakukan kegiatan tersebut baik secra individu atau kelompok-kelompok kecil. Produk tersebut kemudian dievaluasi apakah sudah mencapai target yang dimaksudkan.

\section{Waktu Pelaksanaan}

Kegiatan pelatihan pembuatan media tanam berbahan kain bekas dilaksanakan pada 26 dan 27 Agustus 2017 bertempat di Perumahan Sawang Permai RW XI, Kelurahan Buliang, Kecamatan Batu Aji, Kota Batam. Koordinator dan anggota disini berperan sebagai pemateri sekaligus sebagai instruktur dalam pembuatan media tanam berbahan pakaian dan kain bekas yang tidak layak pakai. Sehingga koordinator dan seluruh anggota terjung kelapangan dan ikut berbaur dengan warga.

\section{PEMBAHASAN}

\section{Sebelum Hari Pelaksanaan}

Langkah awal kegiatan, yaitu penyampaian gagasan pelaksanaan pengabdian kepada Ketua RT dan RW di Perumahan Sawang Permai RW XI, Kelurahan Buliang, Kecamatan Batu Aji, Kota Batam. Dari awalnya gagasan tersebut disambut baik dan berjalan dengan baik oleh warga perumahan. Sehingga memberi semangat bagi tim bisa memulai kegiatan tersebut

\section{Pelaksanaan Kegiatan Pelatihan}

Pada hari pertama, yakni pada tanggal 26 agustus, tim melakukan suatu demonstrasi dengan menyampaikan cara pembuatan media tanam berbahan pakaian dan kain bekas, adapun bahan bahan dan peralatan yang disediakan adalah;

1. Pakaian bekas atau kain bekas yang tidak layak pakai 
Bahan ini merupakan salah satu bahan utama, sebab bahan ini merupakan media yang digunakan untuk dicampurkan dengan semen sehingga semen cair memiliki wadah tempelan.

2. Semen

Semen yang sudah dicapur dengan air dengan ukuran perbandingan $3 \mathrm{~kg}$ semen dicampur air sekitar tiga atau empat liter atau dengan kata lain sekitar 40\% kandungan semen sedangkan kandungan air sekitar $60 \%$ dari total kekentalan campuran bahan. campuran semen dengan air ini berfungsi sebagai perekat pakaian bekas dan kain bekas sehingga setelah dikeringkan maka menjadi keras dan bisa menahan beban tanah yang di isi di dalamnya.

3. Alat cetak seperti ember, pot, kaleng, dan lain-lain

Kain bekas atau pakain bekas dicelupkan ke dalam campuran air dan semen, maka didiamkan beberapa menit, agat campuran semen dengan air bisa meresap kedalam kain bekas dan pakaian bekas. Setelah itu, diangkat dari campuran tersebut dan diletakkan di wadah cetak yang tersedia untuk membentuk pola sesuai dengan keinginan hati. Setelah itu dikeringkan di bawah sinar matahari sampai kering. Untuk mempermudah pemisahan media tanam yang dicetak dengan cetakan, maka ember atau media cetak tersbut dilapisi dengan plastik agar tidak lengket pada media cetak. Setelah kering maka media tanam tersebut dipisahkan dari media cetak.

4. Pilox

Setelah media tanam dipisahkan dari media cetak, maka media tanam tersebut sebenarnya sudah sudah jadi dan bisa dipergunakan, tetapi untuk memperindah dan mempercantik media tanam tersebut, maka dilakukan penegcatan dengan pilok warna warni atau sesuai dengan warna yang diinginkan,

\section{Gunting}

Sebelum melakukan pengecatan, maka sebaiknya dilakukan perapian dengan cara menggunting bagian bagian yang dianggap tidak perlu. Berikut foto dari proses pembuatan media tanam berbahan kain bekas dan pakaian bekas yang tidak layak pakai. 
Adapun kegiatan hari kedua yakni tangal 27 agustus 2017, adalah menunjukkan hasil dari apa yang telah dilakukan pada hari pertama. Setelah adanya hasil tersebut maka warga perumahan bisa melihat langsung hasilnya. Dan pada hari kedua tersebut warga perumahan diminta untuk membawa kain bekas dan pakaian bekas untuk digunakan pembuatan media tanam. Pada hari kedua, warga perumahan sudah ikut langsung membuat dan mencetak media tamnam sesuai dengan keinginan masing-masing. Selama kegiatan tersebut, tim selalu siap siaga untuk membantu dan menjawab pertanyaan dan kesulitan yang dihadapi warga, sehingga warga bisa melakukan sendiri dan memahami langkah-langkah pembuatannya.

Berdasarkan kegiatan yang dipaparkan diatas, maka dapat diperoleh hasil bahwa warga sangat senang dengan kegiatan tersebut dan merasa terbantu mengatasi persoalan pengadaan media tanam. Hal tersebut merupakan suatu pertanda bahwa kegiatan tersebut berdampak positif bagi warga perumahan.

Dengan adanya kegiatan pelatihan ini, maka warga bis memanfaatkan pakaian bekas dan kain bekas yang sudah tidak layak pakai menjadis sesuatu hal yang berguna. Dengan mengkolaborasikan bahan tersebut dengan semen cair maka bisa mencetak media tanam, yang bisa digunakan untk menanam bunga dan juga tanaman yang berumur pendek seperti sayur, cabai, toman dn palawija yang cocok untuk tanaman pot.

Selain itu, menurut pengakuan ibu-ibu PKK dengan adanya pelatihan ini, maka memiliki dampak terhadap pengeluaran dapur seperti sayur mayur sehingga bisa melakukan saving cost. Selain bahan yang mudah dan terjangkau maka hal tersebut menjadi sangat mudah bagi warga dan hal itu terlihat dengan banyaknya warga yang memilik media tanam berbahan pakaian bekas dan kain bekas yang tidak layak pakai yang diletakkan di depan rumah masing-masing. Begitu juga Ketua RT dan Ketua RW semakin gencar mendorong warga membuat media tanam tersebut dibeberap lokasi strategis di perumahan tersebut.

Adapun kendala yang diduga akan terjadi nantinya adalah, ketika media tanam sudah ada tapi ilmu bercocok tanam yang kurang maka dikhawatirkan minat untuk melanjutkan dan menambah media tanam tersebut turun drastis atau bahkan ditinggalkan. Oleh karena itu, tim merasa masih perlu dilakukan pelatihan di perumahan tersebut dengan tema budi daya 


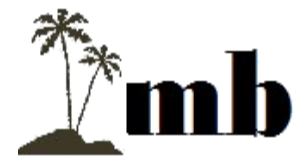

tanaman hias dan sayur mayur pada media tanam, sehingga kebergunaan pelatihan ini bisa dirasakan dan dinikmati oleh warga.

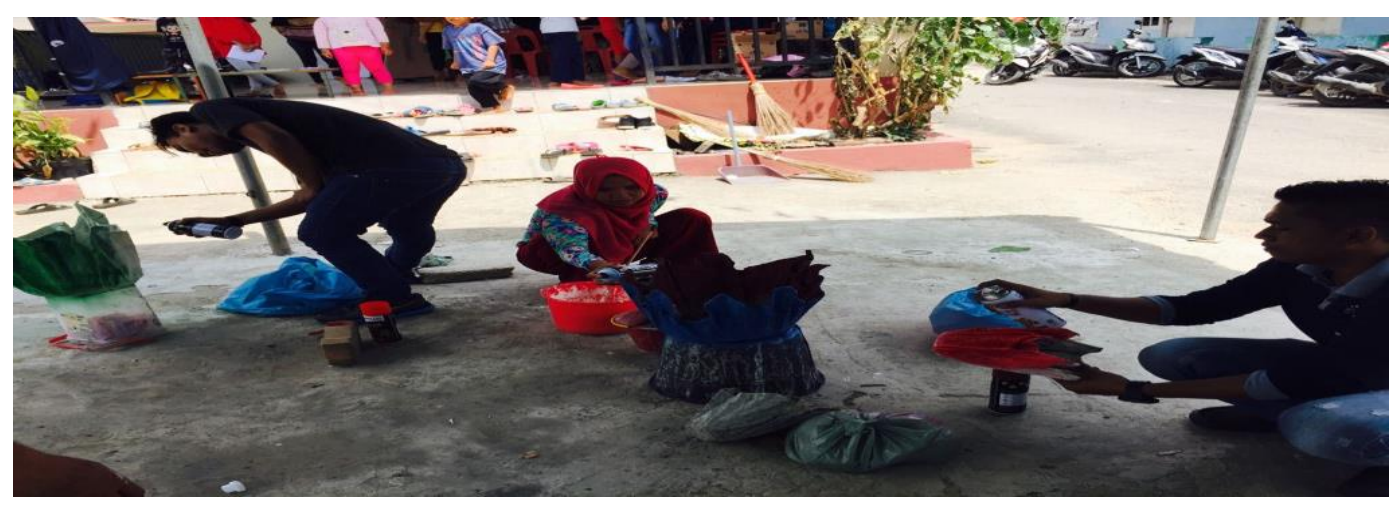

Figur 1. Gambar Proses Penakaran Ukuran Bahan Semen dan Kain Bekas.

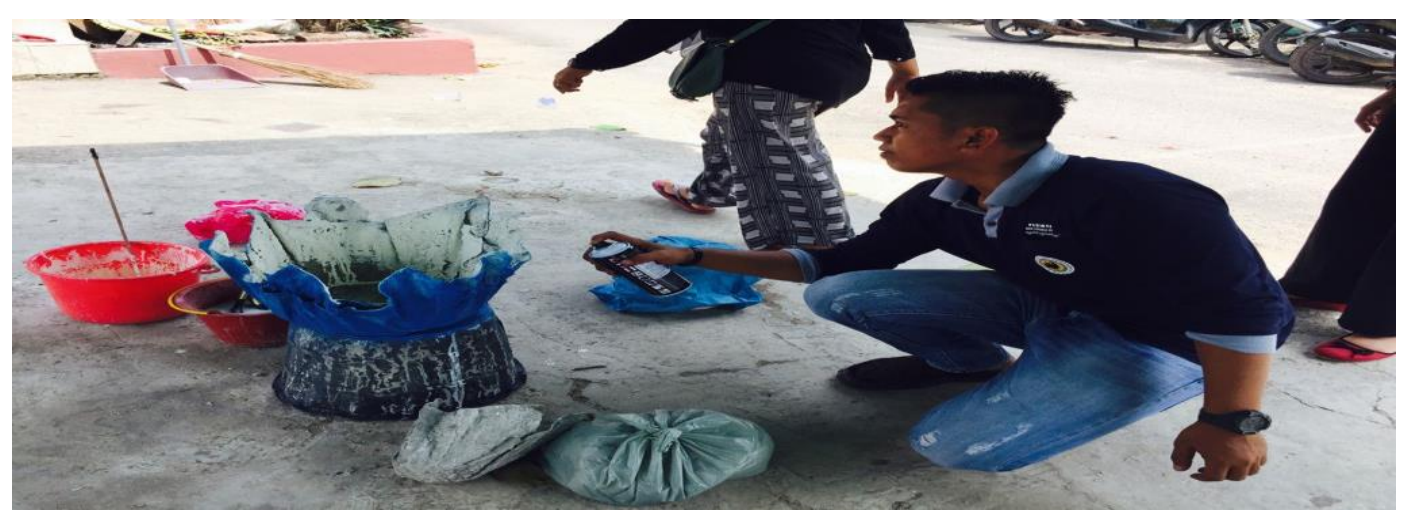

Figur 2. Gambar Pewarnaan Media Tanam Denggan Menggunakan Pilox. 


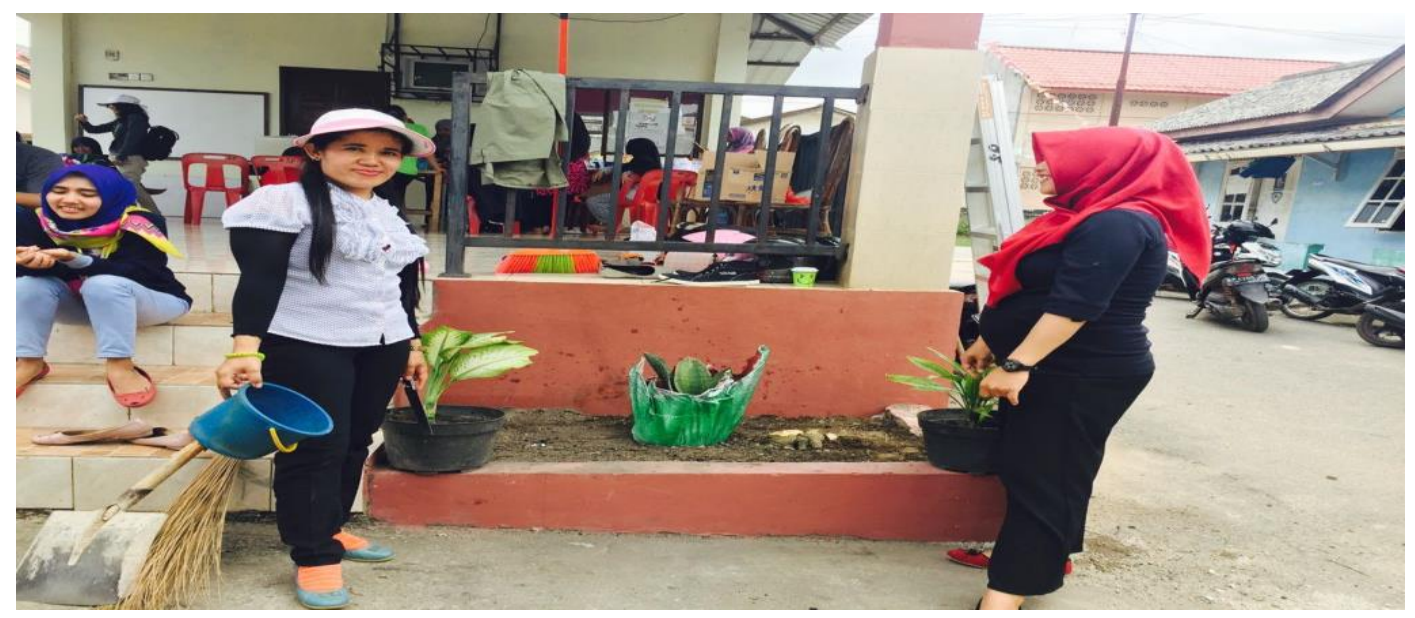

Figur 3. Gambar Media Tanam di Fasum Perumahan Sawang Permai.

\section{KESIMPULAN DAN SARAN}

Berdasarkan uraian pada hasil dan pembahasan di atas, maka dapat disimpulkan sebagai berikut:

1. Pelaksanaan kegiatan pelatihan pembuatan media tanam berbahan pakaian bekas dan kain bekas kategori baik dan lancar.

2. Warga merasa terbantu dengan adanya kegiatan ini, sehingga menumbuhkan minat tanam warga utamanya tanaman hias dan sayur mayur dengan menggunakan media tanam pot dengan biaya yang relatif rendah.

3. Dengan adanya pelatihan ini, maka warga dapat menggunakan pakaian bekas dan kain bekas menjadi sesuatu hal yang berguna dan bisa membantu kebutuhan dapur.

4. Dengan adanya pelatihan ini, maka perumahan menjadi lebih asri dan indah dipandang mata karena banyaknya tanaman dalam media tanam pot yang berwarna warni yang tersusun rapi dan tertata baik.

Adapun saran-sarannya adalah;

1. Untuk mengurangi pencemaran lingkungan yang diakibatkan oleh sampah rumah tangga seperti pakaian dan kain bekas yang tidak layak pakai lagi, maka disarankan 
dijadikan menjadi media tanam. Media tanam tersebut ditanami tanaman hias atau tanama sayur mayur.

2. Selain sebagai media tanam, tim berkeyakinan bahwa masih banyak lagi hal-hal yang bisa dimanfaatkan darsampah dengan menggunakan 3R (Reuse, Recycle, dan Reduce).

\section{REFERENSI}

Peraturan Pemerintah no. 81 tahun 2012 tentang Pengelolaan Sampah Rumah tangga dan Sampah sejenis Sampah Rumah Tangga

Undang-Undang Republik Indonesia Nomor 18 Tahun 2008 Tentang Pengelolaan Sampah

UNRIKA, LPPM. 2017. Panduan Pengabdian Pada Masyarakat Lembaga Penelitian dan Pengabdian pada Masyarakat (LPPM) Universitsa Riau Kepulauan. Batam, LPPM UNRIKA.

Puspitawati, Yuni., Mardwi Rahdriawan. 2012 . Kajian Pengelolaan Sampah Berbasis Masyarakat dengan Konsep 3R (Reduce, Reuse, Recycle) di Kelurahan Larangan Kota Cirebon. Jurnal pembangunan wilayah \& kota : 8 (4): 349-359.

Yuwono, Nasih Widya. 2010. Pengelolaan Sampah Yang Ramah Lingkungan Di Sekolah. Makalah disampaikan pada " Pelatihan Pengembangan Sekolah Hijau Untuk Guru-Guru Smk Rsbi Se-Diy”, Lppm Ugm Bekerja Sama Dengan Dinas Pendidikan, Pemuda Dan Olah Raga Provinsi DIY, Yogyakarta: 25-28 Oktober 2010.

http://batamtoday.com/batam/read/81234/Volume-Sampah-Terus-Meningkat-DKP-BatamTambah-72-Bin-Kontainer 